\title{
A new frontier approach to model the eco-efficiency in European countries ${ }^{1}$
}

\author{
Margarita Robaina Alves $^{\mathrm{a} *}$, Victor Moutinhob $^{\mathrm{b}}$, Pedro Macedo ${ }^{\mathrm{c}}$ \\ aGOVCOPP - Research Unit in Governance, Competitiveness and Public Policy, and Department of \\ Economics, Management and Industrial Engineering, University of Aveiro, Campus de Santiago, \\ 3810-193, Aveiro, Portugal, mrobaina@ua.pt \\ bCEFAGE - Center of Advanced Studies in Management and Economics, University of Évora, \\ Portugal and Department of Economics, Management and Industrial Engineering, University of \\ Aveiro, Campus de Santiago, 3810-193, Aveiro, Portugal, vmoutinho@ua.pt \\ 'CIDMA - Center for Research and Development in Mathematics and Applications, Department of \\ Mathematics, University of Aveiro, Campus de Santiago, 3810-193, Aveiro, Portugal, \\ pmacedo@ua.pt \\ ${ }^{*}$ Contact author
}

\begin{abstract}
This study aims to evaluate the resource and environment efficiency problem of European countries. We specify a new stochastic frontier model where Gross Domestic Product (GDP) is considered as the desirable output and Greenhouse Gases (GHG) emissions as the undesirable output. Capital, Labour, Fossil fuels and Renewable Energy consumption are regarded as inputs. GDP/GHG ratio is maximized given the values of the other four variables. The study is divided into two distinct periods: 2000-2004 and 2005-2011. This division is related to the implementation of the Kyoto Protocol in 2005, and will allow us to evaluate the difference between the levels of efficiency before and after the establishment of environmental targets. Since stochastic frontier models are typically ill-posed, a new maximum entropy approach to assess technical efficiency, which combines information from the data envelopment analysis and the structure of composed error from the stochastic frontier approach without requiring distributional assumptions, is presented in this work.
\end{abstract}

Keywords: Eco-efficiency, European countries, Renewable energy, Stochastic frontier approach.

${ }^{1}$ Final version of this paper is published in the Journal of Cleaner Production 103 (2015) 562-573. (http://dx.doi.org/10.1016/j.jclepro.2015.01.038) 


\section{Introduction}

Economic activities use production factors as energy resources, labour and capital to produce desirable goods and services, but simultaneously produce undesirable outputs, such as Greenhouse Gases (GHG), and particularly, Carbon Dioxide (CO2) emissions. According to the IPCC report (2007), the energy consumption of fossil fuels such as coal, oil and natural gas is the major contributor towards the increase of GHG emissions including CO2. Thus, if the energy is used inefficiently, this will lead to higher emission levels. It becomes necessary to base the economic, the energy and the environmental policies on the efficient use of resources, in particular on energy efficiency.

But environmental efficiency cannot be separated from economic efficiency. Both help to ensure the competitiveness of a country's economy as well as its environmental sustainability and energy security. In addition, the full range of environmental issues and globalization of economies means that policies are increasingly global. Furthermore, for policymaking it is necessary to have indicators in this context, that is, indicators of economic and environmental efficiency, which compare the evolution of countries or sectors, set goals and implement effective policies, either globally or locally.

Economic efficiency can be divided in technical efficiency (which reflects the ability of a production unit to obtain maximal output from a given set of inputs and the production technology) and allocative efficiency (which reflects the ability of a production unit to use the inputs in optimal proportions given their prices and the production technology).

Economic efficiency does not imply environmental efficiency, as the production processes may rely too much on fossil fuels or technologies, which although technically efficient, and cheap, lead to high levels of emissions or other environmental impacts. But if there is technical or economic inefficiency, it can cause environmental inefficiency. For example, waste of raw materials, or inefficient use of energy leads to a technical, economic and environmental inefficiency also because we are wasting resources and increasing pollution. 
The study of economic and environmental efficiency, at the macroeconomic level for several European countries, is of great relevance to reveal how has been the path in this field, but also to inform policy makers about the economic environmental efficiency of their countries and if there is need to amend or introduce new policies. Bluhdorn and Welsh (2007) suggest that we are in a new era and that ecopolitics needs a new environmental sociology. They pose an important question, at the same time that call ecopolitics the politics of unsustainability: "How do advanced modern capitalist consumer democracies try and manage to sustain what is known to be unsustainable"?

Technological optimists believe that innovation is a key to produce more with less. Progress would be enough to generate the decoupling of economic growth and impact on nature (Lovins, 1998, 2011; Lomborg, 2001). In other words, it would be possible to obtain economic growth and at the same time reduce our absolute demand for natural resources. In another line are technological pessimists that say that in the context of a much more dynamic and populous world, technology alone is not enough to solve all the challenges (Alexander, 2014). So in the future, countries will need to develop without economic growth: the so-called "steady state". GDP may not be the barometer for measuring the health and well-being of economies.

The study of Eco-efficiency, joining the economic and environmental parameters together, may respond, or at least illuminate the readers about the sustainability of these theories.

There are several ways to measure the so-called Eco-Efficiency (EE), which depend on the purpose and scope of the study. Wursthorn el al. (2011) argues that "there is an intensive discussion and widespread research on eco-efficiency, which are concerned with different scopes and scales (see for example the special issue of Ecological Economics 2009, volume 68, issue 6)”. 
As defined by the World Business Council for Sustainable Development (WBCSD), "eco-efficiency is achieved by the delivery of competitively priced goods and services that satisfy human needs and bring quality of life, while progressively reducing ecological impacts and resource intensity throughout the life-cycle to a level at least in line with the Earth's estimated carrying capacity." The concept is concerned with creating more value with less impact (www.wbcsd.org).

In the same line of thought, ISO 14045 defines Eco-efficiency as a quantitative tool for management, which allows studying the environmental impacts of a product throughout its life cycle (Life Cycle Assessment (LCA)), as recommended by previous ISO 14040 and ISO 14044. Thus, EE has three goals: to increase the value of the service or good, to optimize the use of resources, and to reduce the environmental impact. LCA is used at product or enterprise level. At national level it will be more complex and cumbersome to apply it.

Other definitions of EE can be pointed, as "the efficiency with which ecological resources are used to meet human needs", by OECD (1998) or "the ability of firms, industries or economies to produce goods and services while incurring less impact on the environment and consuming fewer natural resources" by Picazo-Tadeo et al. (2011).

The simplest indicator of EE relates the economic output or Gross Domestic Product (GDP) with the environmental impact caused by the production process, for instance, the ratio GDP/CO2. As the production process may give rise to other environmental impacts, other measures, that replace CO2 by a composite good of environmental pressures, have emerged (Schmidheiny and Zorraquin, 1996).

This study aims to evaluate the resource and environment efficiency (Ecoefficiency) problem of European countries. We specify a new stochastic frontier model where GDP is considered as the desirable output and GHG emissions as the undesirable output. We use the ratio between GDP and GHG emissions as definition of EE. Fossil fuel consumption, Renewable Energy Consumption, Capital and Labour are regarded as inputs. GDP by GHG emissions ratio is maximized 
given the values of the other three variables. EE will be greater when the emissions decrease to the same value of GDP, when production is greater for the same amount of emissions, or simultaneously when production increases and GHG emissions shrink.

The study is divided into two distinct periods: 2000-2004 and 2005-2011. This division is related to the implementation of the Kyoto Protocol in 2005, and will allow us to evaluate the difference between the levels of eco-efficiency before and after the establishment of environmental targets.

Since stochastic frontier models are typically ill-posed, many researchers claim the urgent need to develop robust estimation techniques. Recently, maximum entropy estimators have been used in the literature as powerful alternatives to traditional estimators in the estimation of stochastic frontier models. In this study, a stochastic frontier approach using some maximum entropy estimators is proposed as an alternative to the Kaya identity. A new maximum entropy approach to assess technical efficiency, which combines information from the data envelopment analysis (DEA) and the structure of composed error from the stochastic frontier analysis (SFA) without requiring distributional assumptions, is presented in this work.

In this work technical efficiency was estimated, but as the maximized output is the GDP/GHG ratio, the estimation of technical efficiency is also a measure of ecoefficiency.

The article is made up of five sections, including this introduction. Section 2 summarizes the literature that study EE, namely with DEA technique. Section 3 presents data and methodology. Section 4 presents the main results and discussion and section 5 summarizes the conclusions. 


\section{Literature Review}

The use of benchmarking and activity analysis or DEA techniques have emerged in recent years as more sophisticated techniques to assess the EE of the countries and/or economic sectors. Several studies have considered the existence of desirable and undesirable outputs of production, in which the environmental effects are seen as undesirable (Färe et al. 1989, 1996, 2004; Chung et al. 1997; Tyteca, 1996, 1997; Zofio and Prieto, 2001; Zhou et al., 2006, 2007). For example, Haynes et al. (1993) use DEA methodology to measure technical efficiency in pollution prevention activities, using chemical as input and chemical waste as output, along with other traditional inputs and outputs.

Some authors study sectoral EE, such as Picazo-Tadeo et al. (2011, 2012), who estimated EE for individual environmental pressures on the agricultural sector. Picazo-Tadeo and Prior (2009) used Directional Distance Functions and DEA to show that technologies where the biggest output producer is not the greatest polluter and those economic activities can diminish environmental damages without compromising the maximization of their output. These authors also made an application to Spanish ceramic tile producers. Mandal (2010) studied EE of the cement industry in India while Barba-Gutierrez et al. (2009) used the Life Cycle Assessment to compare the EE of different household electric appliances using their environmental impact. Kortelainen and Kuosmanen (2005) analyzed four types of environmental pressures, through the EE analysis of road transport in Finland. Egilmez et al. (2014) applied Economic Input-Output Life Cycle Assessment (EIO-LCA) and DEA, for measuring the eco-efficiency in US manufacturing sectors. Avadí et al. (2014) used the combined LCA + DEA method for examining the eco-efficiency in 13 different fleet segments of fishing vessels, aggregated based on hull capacity of the vessels. Zhu et al. (2014) used the same combined methodology to evaluate the eco-efficiencies of ten comparable pesticides. They considered as inputs: chemical oxygen demand, ammonia nitrogen and hazardous solid waste during the process of producing pesticides. 
Wursthorn et al. (2011) present and discuss a new approach for monitoring ecoefficiency at the level of industry, using emission data released by the European Pollutant Emission Register (EPER) and the Eco-Indicator 99, a single-score lifecycle impact assessment (LCIA) method. The authors make a detailed analysis of eco-efficiency pattern of an economy without being constrained to a small set of highly aggregated sectors. The study covers a wide range of emissions and demonstrates that environmental intensity can serve as an instrument for analysing the structure of an economy's environmental-economic performance. However, disaggregated indicators are needed to better understand the ecoefficiency of economies. A disaggregated indicator should consider the ecoefficiency of branches, which could also be seen as the missing link between the activities of individual companies and the macroeconomic level or, in other words, as a means of connecting the micro level with the macro-level performance of societies (Huppes, 2007, Huppes and Ishikawa, 2009).

Other studies allow for dynamic effects and use panel data, a methodology called DEA window analysis (Charnes and Cooper, 1985). Halkos and Tzeremes (2009) applied this methodology to 17 OECD countries and calculated their EE, building an efficiency ratio (good efficiency through good output, due to a poor measure of efficiency using a bad output). This sort of ratio had already been used in other studies such as Färe et al. (1999) and (2003), Zaim et al. (2001) and Zaim (2004).

The use of DEA to do cross country and over time comparisons of EE has been used in various studies. For example, Taskin and Zaim (2000) measured EE for 52 countries and concluded that high income countries are more efficient than low and middle income countries, despite not having seen significant changes over time in either groups, and Zaim and Taskin (2000) measured the environmental performance of 25 countries and found the existence of the EKC hypothesis. Rashidi et al. (2014) have been incorporated Slacks-Based Measure and Range Adjusted Measure (SBM and RAM models), including as inputs energy (coal and petroleum consumption) and non-energy (Labor force and precipitation average), and as outputs desirable output and undesirable CO2 emissions. The relationship between energy inputs consumption and undesirable outputs production has been 
explained by two informative indices whereby energy saving potential and undesirable output abatement potential is estimated. They also deduced that countries producing high undesirable outputs may not operate eco-efficiently and thus have extreme potential to save energy resources, and countries consuming low energy inputs may operate eco-efficiently and have a low potentiality to reduce undesirable outputs.

According to this literature review, particularly at the macro level, there are scarce studies that analyze and evaluate the environmental and technical efficiency, particularly in the application of stochastic frontier parametric models. In light of this gap in the literature and the relevance of this topic, there is an urgent need to develop robust estimation techniques. In this study, the parametric stochastic frontier approach using some maximum entropy estimators, namely the generalized maximum entropy and the generalized cross-entropy are proposed.

\section{Data and Methodology}

\subsection{Data}

GDP is the Gross Domestic Product at market prices and at constant prices of the year 2000, in Millions of euro (source: Eurostat). GHG are the total Greenhouse Gas Emissions (CO2 equivalent) in thousands of tonnes (source: European Environment Agency). Fossil fuel consumption is the sum of Final Energy Consumption of solid fuels, gas and petroleum products, in thousands of tonnes of oil equivalent (TOE) (source: Eurostat). Renewable Energy Consumption is the Final Energy Consumption of renewable and wastes in thousands of TOE (source: Eurostat). For the variable Capital we considered the Gross fixed capital formation at constant prices of the year 2000, in Millions of euro (source: Eurostat). Labour is total employment (source: Eurostat). The GDP/GHG ratio is the output and the other four variables are considered as inputs by using a log-linear Cobb-Douglas production function.

We considered data for the periods 2000-2004 and 2005-2011 for the following countries: Belgium, Bulgaria, Czech Republic, Denmark, Germany, Estonia, Ireland, 
Greece, Spain, France, Italy, Cyprus, Latvia, Lithuania, Luxembourg, Hungary, Netherlands, Austria, Poland, Portugal, Romania, Slovenia, Slovakia, Finland, Sweden and United Kingdom.

\subsection{Methodology}

Technical efficiency can be computed comparing the observed output and the potential output of a production unit. Thus, technical efficiency analysis is a fundamental tool to measure the performance of the production activity. Several methods to estimate technical efficiency are available in the efficiency literature, being DEA and the stochastic frontier analysis (SFA) the most dominant methods.

The DEA method (Charnes et al., 1978) is based on the previous work of Afriat (1972), Boles (1966), Bressler (1966), Farrell (1957), among others. DEA uses linear programming to construct a non-parametric piece-wise linear production frontier using different return to scales, and the possibility of multiple inputs and multiple outputs. Some well-known DEA models are illustrated in Coelli et al. (2005). It is important to note that since DEA does not account for noise, all deviations from the production frontier are estimated as technical inefficiency. The literature on DEA is massive; see, for example, Charnes et al. (1978) and Cooper et al. (2007) for a brief review.

Aigner et al. (1977), Battese and Corra (1977) and Meeusen and van den Broeck (1977) were the pioneers of the SFA methodology. The general stochastic frontier model is given by

$\ln y_{n}=f\left(\boldsymbol{x}_{n}, \boldsymbol{\beta}\right)+v_{n}-u_{n}$

where $N$ is the number of producers $(n=1,2, \ldots, N), f($.$) is the production$ frontier, $y_{n}$ is the scalar output for producer $n, \boldsymbol{x}_{n}$ is a row vector with logarithms of inputs, $\boldsymbol{\beta}$ is a column vector of parameters to estimate, $v$ is a random variable representing noise (measurement errors and/or random shocks) and $u \geq 0$ is a one-sided random variable representing technical inefficiency. The random variable $v$ is usually assumed to be normally distributed, $N\left(0, \sigma_{v}^{2}\right)$, and $u$ is defined 
through different distributions such as exponential, non-negative half normal, truncated normal or gamma. It is assumed that $v$ and $u$ are independently distributed of each other.

The output-oriented measure of technical efficiency is defined by

$\mathrm{TE}_{n}:=\frac{y_{n}}{\exp \left(f\left(\boldsymbol{x}_{n}, \boldsymbol{\beta}\right)+v_{n}\right)}=\frac{\exp \left(f\left(\boldsymbol{x}_{n}, \boldsymbol{\beta}\right)+v_{n}-u_{n}\right)}{\exp \left(f\left(\boldsymbol{x}_{n}, \boldsymbol{\beta}\right)+v_{n}\right)}=\exp \left(-u_{n}\right)$,

which represents the ratio of the observed output to the potential output for the $n$th producer. The potential output is defined by the stochastic production frontier $\exp \left(f\left(\boldsymbol{x}_{n}, \boldsymbol{\beta}\right)+v_{n}\right)$. Naturally, $\mathrm{TE}_{n}$ assumes values between zero and one.

The parameters of model (1) are usually estimated through maximum likelihood (ML). Kumbhakar and Lovell (2000, pp. 74-90) presented all the estimation procedures with the ML estimator for different distributional assumptions required for the two-error components. It is important to note that this is the main criticism on SFA, in particular the choice of the distribution for the $u$ error component, since different distributional assumptions can lead to different estimates of technical efficiency. However, on the other hand, the main advantage of SFA is the structure of the composed error which separates the impacts on production outside the producer's control (strikes, bad weather, luck) from technical efficiency. The technical efficiency estimates with ML are obtained in this work using "frontier" package in R (Coelli and Henningsen, 2013).

An alternative to ML is the maximum entropy (ME) estimation. The ME formalism was first established by Jaynes (1957a,b) based on physics (the Shannon entropy and statistical mechanics) and statistical inference. The ME principle provides a tool to make the best predictions from the (usual limited) available information. Provided that the entropy function is maximized without the model constraint a solution from a uniform distribution is obtained and thus the ME principle can be seen as an extension of Bernoulli's principle of insufficient reason.

Golan et al. (1996) generalized the $\mathrm{ME}$, as well as the cross-entropy (CE) formalism, and developed the generalized maximum entropy (GME) and 
generalized cross-entropy (GCE) estimators, which can be used in models exhibiting collinearity, in models with small samples sizes (micronumerosity) and non-normal errors, as well as in models where the number of parameters to be estimated exceeds the number of observations available (under-determined models).

Recently, an increasing interest with these estimators in technical efficiency analysis has emerged in the literature; e.g., Campbell et al. (2008), Rezek et al. (2011), Macedo et al. (2014) and Macedo and Scotto (2014). The main motivation comes from the advantages of the ME estimation which avoids criticisms and difficulties of DEA and SFA. For instance, with ME estimation the DEA method is used only to define an upper bound for the supports and thus the main criticism on DEA is used as an advantage. Furthermore, the composed error structure in SFA is used without distributional assumptions, which means that the main criticism on SFA is avoided with ME estimation. Thus, by avoiding criticisms and difficulties of DEA and SFA, the ME estimators appear to be a promising approach in efficiency analysis.

Considering the stochastic frontier model in (1) defined in matricial form by $\ln \boldsymbol{y}=f(\boldsymbol{X} ; \boldsymbol{\beta})+\boldsymbol{v}-\boldsymbol{u}$,

the reparameterization of the $(K \times 1)$ vector $\boldsymbol{\beta}$ and the $(N \times 1)$ vector $\boldsymbol{v}$ follows the same procedures as in the traditional regression model. Each parameter is treated as a discrete random variable with a compact support and $2 \leq M<\infty$ possible outcomes and each error is defined as a finite and discrete random variable with $2 \leq J<\infty$ possible outcomes. Thus, the reparameterizations are given by $\boldsymbol{\beta}=\boldsymbol{Z} \boldsymbol{p}$, with $\boldsymbol{Z}$ being a $(K \times K M)$ matrix of support points, $\boldsymbol{p}$ a $(K M \times 1)$ vector of unknown probabilities; and $\boldsymbol{v}=\boldsymbol{A} \boldsymbol{w}$, with $\boldsymbol{A}$ a $(N \times N J)$ matrix of support points and $\boldsymbol{w}$ a $(N J \times 1)$ vector of unknown probabilities. Extending this idea to the vector $\boldsymbol{u}$, the reparameterization is similar to the one conducted for the random variable representing noise $\boldsymbol{v}$, taking only into account that $\boldsymbol{u}$ is a one-sided random variable which implies that the lower bound for the supports (with $2 \leq L<\infty$ points) is zero for all error values (the full efficiency case). The reparameterization of $\boldsymbol{u}$ can be defined by $\boldsymbol{u}=\boldsymbol{B} \boldsymbol{\rho}$, with $\boldsymbol{B}$ a $(N \times N L)$ matrix of 
support points and $\boldsymbol{\rho}$ a $(N L \times 1)$ vector of unknown probabilities. See, for example, Campbell et al. (2008) and Macedo et al. (2014) for further details.

The GME estimator selects the vectors $\boldsymbol{p}, \boldsymbol{w}$ and $\boldsymbol{\rho}$ which maximize

$H(\boldsymbol{p}, \boldsymbol{w}, \boldsymbol{\rho})=-\boldsymbol{p}^{\prime} \ln \boldsymbol{p}-\boldsymbol{w}^{\prime} \ln \boldsymbol{w}-\boldsymbol{\rho}^{\prime} \ln \boldsymbol{\rho}$,

subject to the model constraint and the additivity constraints, respectively,

$\ln y=X Z p+A w-B \rho$,

$\mathbf{1}_{K}=\left(I_{K} \otimes \mathbf{1}_{M}^{\prime}\right) \boldsymbol{p}$,

$\mathbf{1}_{N}=\left(\boldsymbol{I}_{N} \otimes \mathbf{1}_{J}^{\prime}\right) \boldsymbol{w}$,

$\mathbf{1}_{N}=\left(\boldsymbol{I}_{N} \otimes \mathbf{1}_{L}^{\prime}\right) \boldsymbol{\rho}$,

where $\otimes$ represents the Kronecker product. On other hand, the GCE formulation selects the vectors $\boldsymbol{p}, \boldsymbol{w}$ and $\boldsymbol{\rho}$ which minimize

$H\left(\boldsymbol{p}, \boldsymbol{q}_{1}, \boldsymbol{w}, \boldsymbol{q}_{2}, \boldsymbol{\rho}, \boldsymbol{q}_{3}\right)=\boldsymbol{p}^{\prime} \ln \left(\boldsymbol{p} / \boldsymbol{q}_{1}\right)+\boldsymbol{w}^{\prime} \ln \left(\boldsymbol{w} / \boldsymbol{q}_{2}\right)+\boldsymbol{\rho}^{\prime} \ln \left(\boldsymbol{\rho} / \boldsymbol{q}_{3}\right)$,

subject to the model and additivity constraints (5)-(8).

The support matrices $\boldsymbol{Z}$ and $\boldsymbol{A}$ are defined by the researcher based on prior information. When such information does not exist wide bounds can be used without expecting extreme risk consequences (Golan et al., 1996). In this work, the supports in $\boldsymbol{Z}$ are defined through $[-10,10]$, a conservative choice, with $M=5$. Furthermore, since the vector $\boldsymbol{v}$ is a two-sided random variable representing noise, the supports in the matrix $\boldsymbol{A}$ are defined symmetrically and centered on zero, using the three-sigma rule with the empirical standard deviation of the noisy observations and $J=5$.

Considering the definition of matrix $\boldsymbol{B}$, it is important to note that the traditional distributional assumptions concerning the error inefficiency component (half normal, truncated normal, exponential, gamma, among others) have been used in the empirical literature since it is expected a particular behaviour in the distribution of technical inefficiency estimates. For instance, in the discussion of the normal - half normal model, Kumbhakar and Lovell (2000, p. 74) argued that the choice of the latter distribution (a non-negative half normal) for the inefficiency error component "[...] is based on the plausible proposition that the 
modal value of technical inefficiency is zero, with increasing values of technical inefficiency becoming increasingly less likely."

Thus, an important advantage of the GME and GCE estimators is that distributional assumptions are not necessary but the same beliefs can be expressed in the model through the error supports (in GME) or through a set of subjective probability distribution (in GCE). For example, Campbell et al. (2008) suggested the use of the mean of the DEA and SFA efficiency estimates to define the supports in matrix $\boldsymbol{B}$ with a specific upper bound $(u b)$. Thus, following Campbell et al. (2008) and Rezek et al. (2011) the supports for the GME estimator are defined in this work through $\boldsymbol{b}_{n}^{\prime}=[0,0.01,0.05,0.1, u b]$,

where ub represents a value such that the prior mean establish by (10) is a central value between the DEA and SFA mean technical efficiency estimates. Note that, as mentioned by Rezek et al. (2011, p. 364), the selection "of these vectors sets a prior expectation of mean efficiency; however, it does not preordain that result." This is an important feature of ME estimation.

For the GCE estimator, since only the vector $\boldsymbol{q}_{3}$ is non-uniform, following the prior beliefs mentioned previously, the objective function (9) can be simplified as the minimization of

$H\left(\boldsymbol{p}, \boldsymbol{w}, \boldsymbol{\rho}, \boldsymbol{q}_{3}\right)=\boldsymbol{p}^{\prime} \ln \boldsymbol{p}+\boldsymbol{w}^{\prime} \ln \boldsymbol{w}+\boldsymbol{\rho}^{\prime} \ln \left(\boldsymbol{\rho} / \boldsymbol{q}_{3}\right)$,

being the set of subjective probability distribution established in this work by

$\boldsymbol{q}_{3}=[0.70,0.20,0.05,0.03,0.02]$

for each observation, where the cross-entropy objective shrinks the posterior distribution in order to have more mass near zero, such that the prior mean is a value between the GME and SFA mean technical efficiency estimates. See, for example, Macedo and Scotto (2014) for further details.

In the GCE estimator, the supports in matrix $\boldsymbol{B}$ are defined with five equally spaced points in the range $\left[0,-\ln \left(\mathrm{DEA}_{n}\right)\right]$, where $\mathrm{DEA}_{n}$ represents the lower technical efficiency estimate obtained by DEA in the $N$ observations in the sample. Since all deviations from the DEA production frontier are due to the inefficiency of the producer, the DEA method provides, in general, lower levels of efficiency than SFA, 
which means that DEA can be used to define an upper bound for the supports. Note that although the GCE estimator avoids the choice of the three central values in (10), that define the prior mean and the skewness, it involves the subjective prior weights defined in $\boldsymbol{q}_{3}$. However, it is expected that the GCE estimator remains stable when this prior information is not correct (Golan et al., 1996, p. 142).

Naturally, a very important issue that will deserve further investigation in a near future is the sensitivity analysis on the efficiency estimates given the information provided through the supports in matrix $\boldsymbol{B}$ within the GME estimator, or the vector $\boldsymbol{q}_{3}$ within the GCE estimator, in the same reasoning that Kumbhakar and Lovell (2000, p. 90) answering to the question “Do Distributional Assumptions Matter?", argued that the "sample mean efficiencies are no doubt apt to be sensitive to the distribution assigned to the one-sided error component [...] What is not so clear is whether a ranking of producers by their individual efficiency scores [...] is sensitive to distributional assumptions."

\section{Results and Discussion}

The closer the value of EE is from unit, the more efficient the country is, which means that the country is making the best use of resources to produce the maximum possible and at the same time is minimizing the environmental impact through GHG emissions.

Table 1 presents some descriptive statistics for the estimates obtained through the GME, GCE and ML estimators. Considering the period 2000-2011, the ML estimator provides the higher mean value of EE $(0,7654$ for ML; 0,7538 for GCE; 0,6741 for GME). The standard deviation is also the greatest for the ML estimator, followed by the values for the GME and GCE estimators, respectively. ML estimator provides the lower (0,2679 in 2007 for Estonia) and the higher (0,9921 in 2008 for Latvia) values of EE in this period. Figures A2 in the Appendix illustrate the results from the three estimators in the period 2000-2011. 
Table 1 - Estimates obtained through Generalized Maximum Entropy (GME), Generalized CrossEntropy (GCE) and Maximum Likelihood (ML) estimators - some descriptive statistics

\begin{tabular}{cccccccccccccc}
\hline & \multicolumn{1}{c}{ Mean } & \multicolumn{1}{c}{ Standard Deviation } & \multicolumn{3}{c}{ Minimum } & \multicolumn{2}{c}{ Maximum } \\
\hline & \multicolumn{1}{c}{ GME } & GCE & ML & GME & GCE & ML & GME & GCE & ML & GME & GCE & ML \\
\hline 2000 & 0,6696 & 0,7768 & 0,7834 & 0,0896 & 0,0665 & 0,1093 & 0,4588 & 0,5990 & 0,5257 & 0,8386 & 0,8836 & 0,9304 \\
2001 & 0,6970 & 0,7599 & 0,8147 & 0,0800 & 0,0679 & 0,0818 & 0,5134 & 0,5879 & 0,5928 & 0,8545 & 0,8799 & 0,9290 \\
2002 & 0,6832 & 0,7496 & 0,7853 & 0,0842 & 0,0731 & 0,1111 & 0,4651 & 0,5392 & 0,4612 & 0,8538 & 0,8790 & 0,9365 \\
2003 & 0,6830 & 0,7390 & 0,7763 & 0,0868 & 0,0791 & 0,1183 & 0,4361 & 0,4888 & 0,4068 & 0,8611 & 0,8798 & 0,9372 \\
2004 & 0,6837 & 0,7482 & 0,7825 & 0,0831 & 0,0738 & 0,1188 & 0,4416 & 0,5085 & 0,4108 & 0,8553 & 0,8790 & 0,9430 \\
2005 & 0,6841 & 0,7552 & 0,7795 & 0,0813 & 0,0705 & 0,1263 & 0,4470 & 0,5255 & 0,3937 & 0,8406 & 0,8714 & 0,9456 \\
2006 & 0,6705 & 0,7544 & 0,7516 & 0,0832 & 0,0696 & 0,1530 & 0,4315 & 0,5279 & 0,3218 & 0,8273 & 0,8667 & 0,9566 \\
2007 & 0,6636 & 0,7531 & 0,7477 & 0,0915 & 0,0774 & 0,1841 & 0,3955 & 0,4950 & 0,2679 & 0,8158 & 0,8613 & 0,9847 \\
2008 & 0,6569 & 0,7519 & 0,7205 & 0,0889 & 0,0728 & 0,1800 & 0,4153 & 0,5262 & 0,3114 & 0,8031 & 0,8559 & 0,9921 \\
2009 & 0,6837 & 0,7530 & 0,7671 & 0,0818 & 0,0694 & 0,1381 & 0,5106 & 0,5946 & 0,4610 & 0,8129 & 0,8523 & 0,9399 \\
2010 & 0,6701 & 0,7561 & 0,7494 & 0,0886 & 0,0734 & 0,1556 & 0,4493 & 0,5529 & 0,3715 & 0,8341 & 0,8725 & 0,9487 \\
2011 & 0,6441 & 0,7486 & 0,7262 & 0,0994 & 0,0834 & 0,1805 & 0,3614 & 0,4755 & 0,2882 & 0,7776 & 0,8429 & 0,9544 \\
\hline \hline
\end{tabular}

Regarding the ranking of countries, the different methods used to evaluate the EE show very similar results. Therefore we will focus on the analysis and interpretation of results concerning modification on the ranking of countries as well as in the trend of EE in the first and the second period (before and after the Kyoto Protocol commitment), considering only the results of the GCE estimator.

In the first period, before the Kyoto Protocol, according to Figure 1 and Table A1 in Appendix, the empirical evidence shows that Sweden, United Kingdom, Latvia, Cyprus and France are the five most efficient countries, while Estonia, Czech Republic and Greece constitute the least efficient countries. Furthermore, as shown in Table 1, Portugal and Slovenia were in the 20th and 17 th position respectively, in 2000 and are ranked in 12th and 10th position on 2004. Conversely, Bulgaria and Italy were ranked at 8 th and 10 th position in 2000 and changed the ranking to 17 th and 18th respectively in 2004. That evidence suggests that Portugal and Slovenia are becoming relatively more efficient, while Bulgaria and Italy became the least economic and environmental efficient countries at the end of the first period of analysis. 
Figure 1- Eco-Efficiency estimates in 2000-2004 provided by the GCE estimator

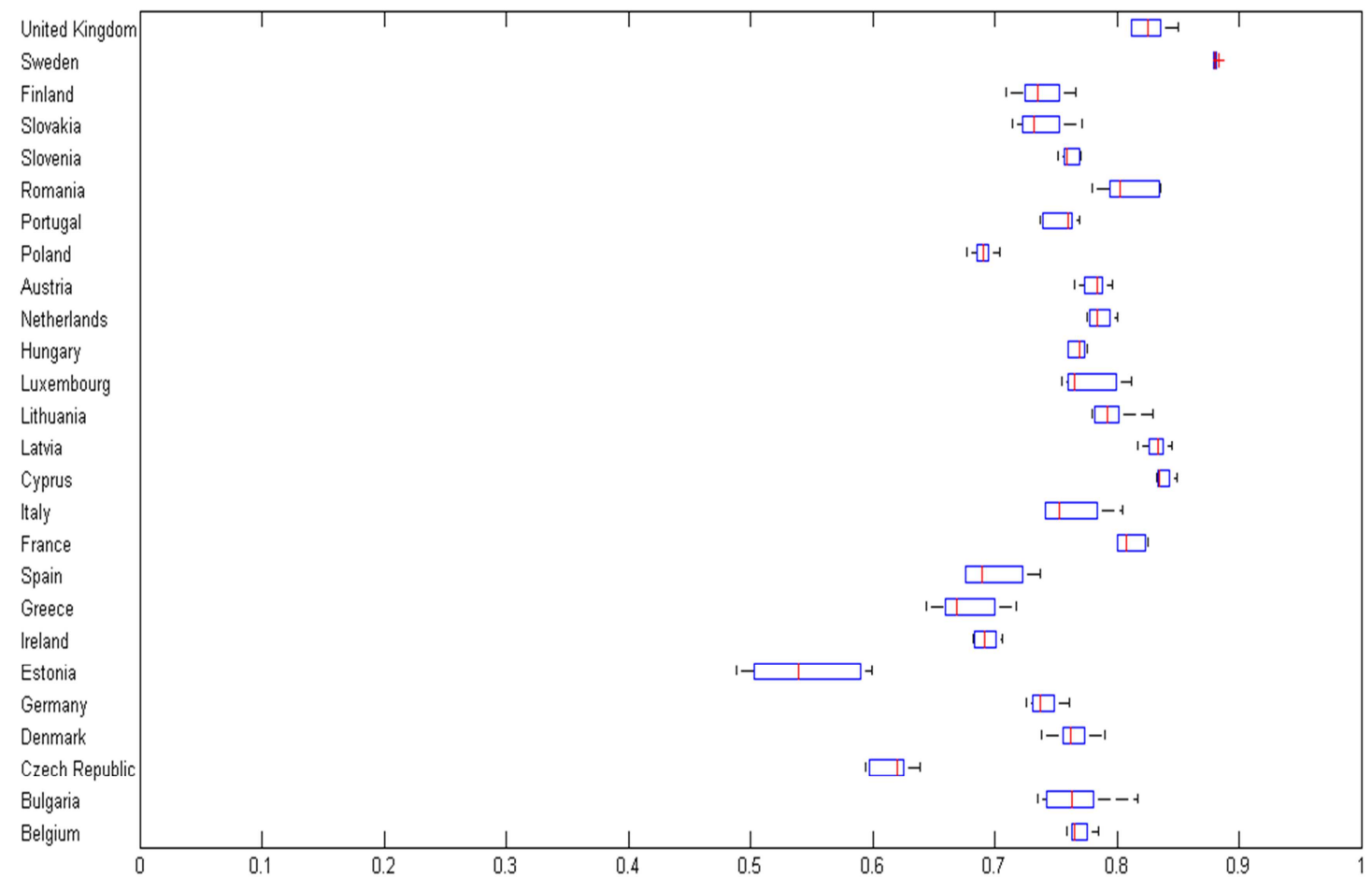

Table 2- Rankings of Eco-Efficiency in European Countries established by the GCE estimator

\begin{tabular}{|c|c|c|c|c|c|c|c|c|c|c|c|c|}
\hline & 2000 & 2001 & 2002 & 2003 & 2004 & 2005 & 2006 & 2007 & 2008 & 2009 & 2010 & 2011 \\
\hline Sweden & 1 & 1 & 1 & 1 & 1 & 1 & 1 & 1 & 2 & 3 & 2 & 1 \\
\hline United Kingdom & 2 & 5 & 4 & 4 & 4 & 3 & 3 & 6 & 3 & 1 & 3 & 6 \\
\hline Latvia & 3 & 3 & 3 & 3 & 3 & 5 & 5 & 3 & 1 & 2 & 1 & 2 \\
\hline Cyprus & 4 & 2 & 2 & 2 & 2 & 2 & 2 & 2 & 5 & 9 & 12 & 8 \\
\hline Romania & 5 & 4 & 6 & 7 & 6 & 4 & 11 & 13 & 17 & 14 & 15 & 11 \\
\hline Lithuania & 6 & 8 & 7 & 6 & 8 & 9 & 10 & 15 & 11 & 4 & 8 & 13 \\
\hline France & 7 & 6 & 5 & 5 & 5 & 7 & 9 & 9 & 10 & 11 & 10 & 9 \\
\hline Bulgaria & 8 & 14 & 12 & 17 & 17 & 20 & 20 & 20 & 24 & 24 & 23 & 23 \\
\hline Luxembourg & 9 & 7 & 10 & 13 & 14 & 15 & 16 & 17 & 18 & 18 & 19 & 22 \\
\hline Italy & 10 & 11 & 16 & 15 & 18 & 18 & 15 & 14 & 13 & 13 & 14 & 15 \\
\hline Netherlands & 11 & 10 & 9 & 8 & 7 & 6 & 8 & 8 & 9 & 7 & 11 & 16 \\
\hline Austria & 12 & 9 & 8 & 10 & 9 & 10 & 7 & 7 & 7 & 8 & 9 & 10 \\
\hline Denmark & 13 & 15 & 13 & 16 & 13 & 11 & 18 & 16 & 16 & 16 & 16 & 17 \\
\hline Belgium & 14 & 12 & 11 & 9 & 15 & 17 & 14 & 12 & 12 & 17 & 17 & 14 \\
\hline Hungary & 15 & 13 & 14 & 12 & 11 & 8 & 4 & 4 & 4 & 5 & 5 & 3 \\
\hline Slovakia & 16 & 21 & 20 & 18 & 16 & 16 & 13 & 10 & 8 & 6 & 13 & 20 \\
\hline Slovenia & 17 & 16 & 15 & 14 & 10 & 12 & 12 & 11 & 14 & 15 & 7 & 5 \\
\hline Finland & 18 & 17 & 19 & 20 & 20 & 14 & 17 & 18 & 15 & 20 & 21 & 12 \\
\hline Germany & 19 & 18 & 18 & 19 & 19 & 19 & 19 & 19 & 20 & 19 & 20 & 21 \\
\hline Portugal & 20 & 19 & 17 & 11 & 12 & 13 & 6 & 5 & 6 & 10 & 6 & 4 \\
\hline Spain & 21 & 20 & 23 & 23 & 23 & 24 & 24 & 23 & 21 & 21 & 18 & 19 \\
\hline Greece & 22 & 22 & 24 & 24 & 24 & 22 & 23 & 24 & 23 & 22 & 22 & 18 \\
\hline Ireland & 23 & 24 & 21 & 22 & 22 & 23 & 21 & 21 & 19 & 12 & 4 & 7 \\
\hline Poland & 24 & 23 & 22 & 21 & 21 & 21 & 22 & 22 & 22 & 23 & 24 & 24 \\
\hline Czech Republic & 25 & 25 & 25 & 25 & 25 & 25 & 25 & 25 & 25 & 25 & 25 & 25 \\
\hline Estonia & 26 & 26 & 26 & 26 & 26 & 26 & 26 & 26 & 26 & 26 & 26 & 26 \\
\hline
\end{tabular}

For the second period analyzed (2005-2011), it can be seen from Figure 2 and Table A1 in Appendix, that Sweden, Latvia, UK, Hungary, Portugal and Cyprus are 
the six most efficient countries, while, Czech Republic, Poland and Estonia, constitute the three least efficient countries.

Figure 2 - Eco-Efficiency estimates in 2005-2011 provided by the GCE estimator

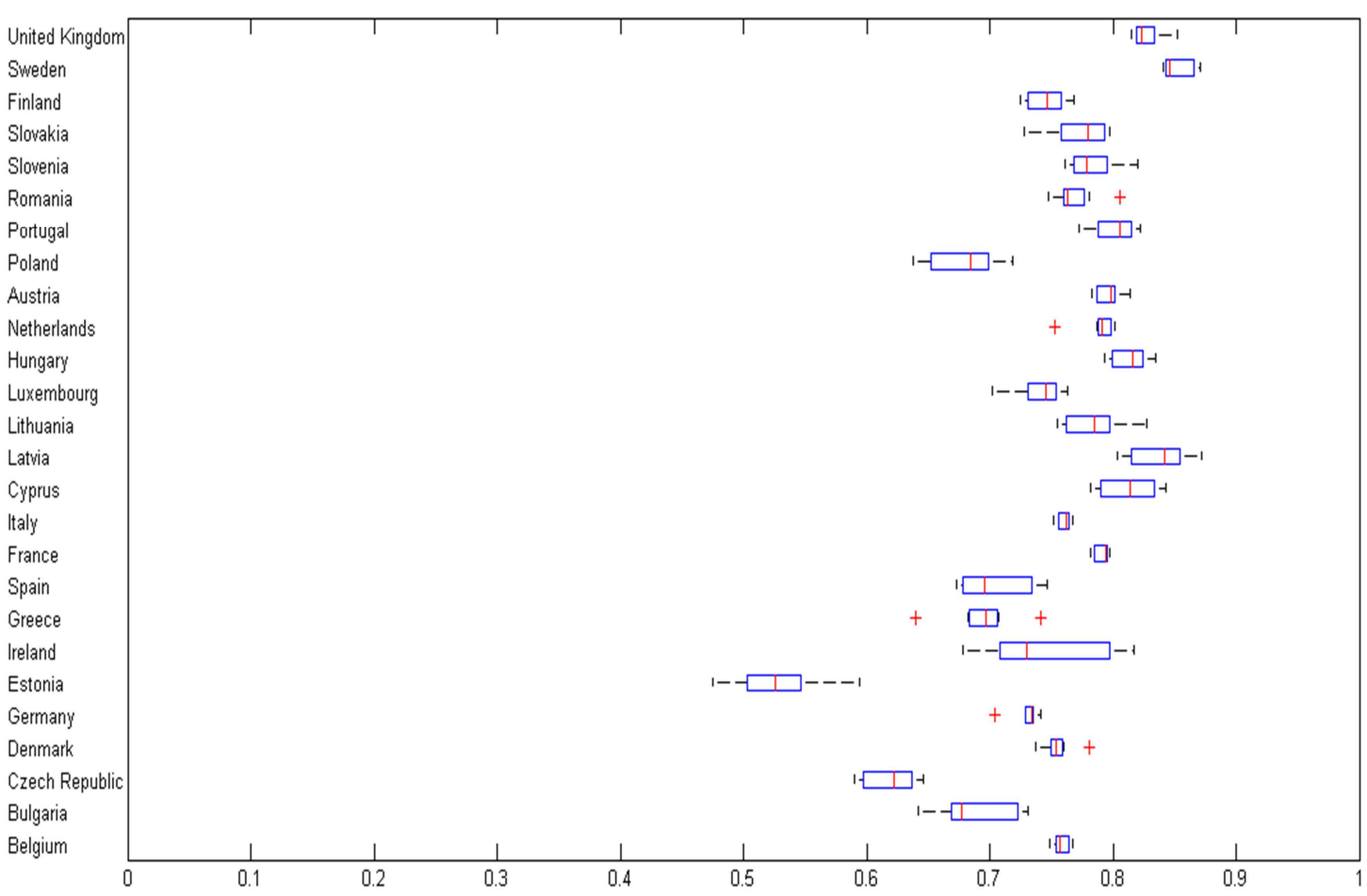

According to Table 2, Hungary, Slovenia, Portugal and Ireland are ranked in 8th, 12th, 13th and 23rd place respectively in 2005 and change their ranking to 3rd, 5 th, 4th and 7th place respectively in 2011. This suggests a significant change in the trend of economic and environmental efficiency. Conversely, Romania, Lithuania and Denmark are ranked in 4th, 9th and 11th place respectively in 2005, and drop position to 11 th, 13 th and 17 th respectively at the end of the period.

The EE estimates using the three estimation techniques (GME, GCE and ML) for these European countries show that changes in energy sources, capital and labour might give a reasonable simultaneous indication of the economic and environmental efficiency improvements. Analyzing the EE path (Table A1), we can point out some relevant facts.

For the period as a whole, we can point out some countries that performed well, such as Ireland, which increased its level of EE by $50 \%$ (from 0.65 to 0.95), Hungary, by $23 \%$ (from 0.77 to 0.95 ), Portugal and Slovenia, by $22 \%$ (from 0.74 to 
0.91 and 0.76 to 0.92 respectively). This good performance was particularly strong in the second period. On the other hand, Bulgaria and Estonia experienced a bad performance overall, by dropping the EE level of 0.83 to $0.53(-36 \%)$ and from 0.54 to $0.29(-47 \%)$ respectively.

Although the EE indicator gives us the overall outcome for the economic and environmental efficiency of the joint use of production factors, such as capital, labour, renewable and non renewable energy sources, it is importantto know what factors lie behind the good performance or the poor performance of the mentioned countries (see Figures A1 in Appendix).

For instance, in the case of Portugal, Ireland and Hungary, the performance seems to be a good combination of improving the average productivity of capital, with a reduction in fossil fuels intensity (improved energy efficiency) and the increased use of renewable energy. In addition to these factors, Slovakia also has significant improvements in average productivity of labour.

For countries with less good performance, the factors that seem to be behind this result are the drop in the average productivity of capital and labour (Italy and Denmark) and the increased intensity of fossil fuels in some years (Romania). In the case of Denmark, there was an increased use of renewable energy, but it probably was not done efficiently.

As in this study the type of efficiency analysis is not only economic, but also environmental, that is, we are considering production per unit of emissions, the source of energy used (fossil or renewable) is crucial to the performance. Countries who bet on renewable energy efficiently, gradually substituting fossil energy, have a greater potential to move closer to the efficiency frontier. Moreover, the best performers are countries pointed by the European Commission (2014) as countries with low energy intensity or with a good performance in terms of energy intensity in the last decade. 
Since the ratification of the Kyoto Protocol, the European countries have taken various initiatives to reduce emissions and this was noted in the evolution of the level of eco-efficiency of some countries, particularly on the second period. The investment in renewable energy seems to be a differentiator of that good behavior. The European Directive 2009/28/EC of the European Parliament and of the Council, sets targets for the promotion of renewable energy use in order to reduce emissions of pollutants and reduce energy dependence on imports. This directive also recognizes the importance of renewable energy for economic growth and for a sustainable energy policy.

Nevertheless, the worst performance of some countries may be being supported by strong lobbies in the area of fossil fuels. This effect combined with the protectionist policies in the energy production sector increases the use of non-renewable sources despite the effective promotion of renewable sources by public policies.

On the other hand, the large variability and uncertainty associated with certain renewable energy causes the energy operators to have to maintain an energy mix, in which fossil fuels are still very important (Kabouris and Kanellos (2010), Halamay and Brekken (2011)). Much of the literature argues that there is a tradeoff between the backup of fossil fuels and renewable use. It is argued that natural gas or coal are energy sources with a higher backup, especially in terms of safety and security of supply, due to the intermittent supply of energy from renewable energy sources. However, the generation of energy from renewable sources (particularly wind power) due to its rapid operational flexibility and connection to transmission networks, responds to fluctuations in demand, as is supported by Dursun and Alboyaci (2010). That is, renewable energy responds to periods of low demand while conventional plants respond to fluctuating demand in the peak-load periods.

Our results are also relevant to identify that the share of renewable and nonrenewable energy sources are important in explaining differences in emissions together with economic growth, capital investment and labour, that is, to explain the different levels of efficiency measured by GDP/GHG ratio for each country in 
the EU-27 panel. Moreover, these results show the importance of the interactive impact of the share of renewable and non-renewable sources, that is, the mix of resources that can simultaneously maximize economic growth without compromising the mitigation of GHG emissions.

As it is necessary to comply with the targets for renewable energy and to lower the costs of renewable energy, countries like Portugal and Spain have implemented policies based on schemes that include feed-in tariffs, feed-in premiums and green certificates. As these countries had high tariff deficits, they combined raises in tariffs with other measures that divide the burden between the energy consumers, the energy sector and public finance. But in Bulgaria, grid access tariffs for renewable energy producers were introduced and at the same time the access to the energy system was enabled for a part of the grid of connected renewable capacity. Bulgaria reduced its tariff deficit, but it had negative effects on the investment of renewable energy (European Commission, 2014).

If we analyze the rate of GDP growth, the fastest growing countries in this period were Bulgaria, Czech Republic, Lithuania, Poland and Slovakia (with average growth rates between $4 \%$ and $8 \%$ ). High growth rates may show that these are less developed countries, and that could be at a stage prior to the turning point of Kuznets curve. Looking to other data we can see that in these countries there is a high rate of growth of labor productivity and of the intensity of the fossil energy consumption, while there is a poor increase in capital productivity. According to our results these countries are among the least efficient from a technical and environmental perspective. Our analysis is in consonance with the Kuznets curve as it suggests that less developed countries have worse technical and environmental efficiency than most developed countries. On the other hand, countries that are more eco-efficient, like Sweden, Cyprus, Latvia and UK are countries whose GDP grew at more moderate rates (on average between - $1 \%$ and $2 \%)$. Therefore countries in a growth phase that may have exceeded the turning point of the Kuznets curve and have become technically and environmentally more efficient. In that way, although our study does not provide direct evidence about it, can somehow strengthen the techno optimistic theory. 


\section{Conclusions}

This study evaluated the Eco-efficiency problem of European countries in two distinct periods: 2000-2004 and 2005-2011. We specified a new stochastic frontier model where the ratio between GDP and GHG emissions is maximized given the values of Fossil Fuel Consumption, Renewable Energy Consumption, Capital and Labour.

We could identify the change in the positioning of the countries in relation to EE in the two periods under review. The most efficient (Portugal, Slovakia, Hungary, Ireland) and the least efficient countries (Bulgaria, Italy, Romania, Denmark) were noted as well as a greater effort to converge to the frontier of efficiency by some countries in the second period of the analysis which coincides with the period after the ratification of the Kyoto Protocol.

Since the ratification of the Kyoto Protocol, the European countries have taken various initiatives to reduce emissions and this was noted in the evolution of the level of eco-efficiency of some countries, particularly in the second period.

Our analysis is in consonance with the Kuznets curve and techno-optimistic theories as it suggests that less developed countries have worse technical and environmental efficiency than most developed countries.

As the focus of this article was for efficiency measures and not for estimated parameters of frontier of production, it does not reveal which factor (labour, capital, or source of energy) is actually behind the good or bad performance of the country in terms of eco-efficiency. It only gives us the result of the combination of these factors for the different countries. A suggestion for future research would be a detailed analysis of the estimated parameters of the production frontier. Another useful approach could be the use of the decomposition analysis to ascertain which are the most relevant factors in determining the countries' eco- efficiency. 


\section{Acknowledgements}

This work is partially supported by Portuguese funds through the CIDMA - Center for Research and Development in Mathematics and Applications, and the Portuguese Foundation for Science and Technology ("FCT - Fundação para a Ciência e a Tecnologia"), within project PEst-OE/MAT/UI4106/2014.

\section{References}

Afriat, S. N. (1972). Efficiency estimation of production functions. Intern. Econ. Rev., 13(3):568-598.

Aigner, D., Lovell, C. A. K., and Schmidt, P. (1977). Formulation and estimation of stochastic frontier production function models. J. of Econ., 6(1):21-37.

Alexander, S. (2014). A Critique of Techno-Optimism: Efficiency without Sufficiency is Lost. WP 1/14. Post Carbon Pathways Project, Melbourne Sustainable Society Institute.

Avadí, A., Vázquez-Rowe, I. and Fréon, P (2014). Eco-efficiency assessment of the Peruvian anchoveta steel and wooden fleets using the LCA+DEA framework Journal of Cleaner Production, Volume 70, Pages 118-131.

Barba-Gutiérrez, Y., Adenso-Díaz, B. and Lozano, S. (2009). Eco-efficiency of electric and electronic appliances: a data envelopment analysis (DEA). Environ. Model. Assess., 14: 439-447.

Battese, G. E. and Corra, G. S. (1977). Estimation of a production frontier model: with application to the pastoral zone of Eastern Australia. Aust. J. Agr. Resour. Ec., 21(3):169- 79.

Blühdorn, I. and Welsh, I. (2007). Eco-politics beyond the paradigm of sustainability: A conceptual framework and research agenda, Environmental Politics, 16:2, 185-205, DOI: 10.1080/09644010701211650.

Boles, J. N. (1966). Efficiency squared - efficient computation of efficiency indexes. In Proceedings of the Thirty Ninth Annual Meeting of the Western Farm Economics Association, 137-142.

Bressler, R. G. (1966). The measurement of productive efficiency. In Proceedings of the Thirty Ninth Annual Meeting of the Western Farm Economics Association, 129136.

Campbell, R., Rogers, K., and Rezek, J. (2008). Efficient frontier estimation: a maximum entropy approach. J. Prod. Anal., 30(3):213-221. 
Charnes, A., and Cooper, W.W. (1985). Preface to Topics in Data Envelopment Analysis. Ann. Oper. Res., 2(1): 59-94.

Charnes, A., Cooper, W. W., and Rhodes, E. (1978). Measuring the efficiency of decision making units. Eur. J. Oper. Res., 2(6): 429-444.

Chung, Y., Färe, R. and Grosskopf, S. (1997) Productivity and undesirable outputs: a directional function approach. J. Environ. Manage., 51: 229- 240.

Coelli, T. J., Prasada Rao, D. S., O'Donnell, C. J., and Battese, G. E. (2005). An Introduction to Efficiency and Productivity Analysis. Springer, New York, 2nd edition.

Coelli, T., Henningsen, A. (2013). frontier: Stochastic frontier analysis. R package version 1.0. http://CRAN.R-Project.org/package=frontier.

Cooper, W. W., Seiford, L. M., and Tone, K. (2007). Data Envelopment Analysis - A Comprehensive Text with Models, Applications, References and DEA-Solver Software. Springer, New York, 2nd edition.

Dursun, B., and Alboyaci, B. (2010). The contribution of wind-hydro pumped storage systems in meeting Turkey's electric energy demand. Renew. Sustain. Energ., 7:1979-88.

European Commission (2014). Energy Economic Developments in Europe, European Economy series 1/2014.

Egilmez, G., Kucukvar, M. and Tatari, O. (2013). Sustainability assessment of U.S. manufacturing sectors: an economic input output-based frontier approach, Journal of Cleaner Production, Volume 53, 15 August 2013, Pages 91-102.

Färe R., Grosskopf S. and Hernandez-Sancho, F. (2004). Environmental performance: an index number approach. Resour. Energy Econ., 26: 343-352.

Färe R., Grosskopf S., Lovell, C.A.K, and Pasurka, C. (1989). Multilateral productivity comparisons when some outputs are undesirable: a nonparametric approach. Rev. Econ. Stat., 71: 90-98.

Färe R., Grosskopf, S. and Tyteca, D. (1996) An activity analysis model of the environment performance of firms: application to fossil-fuel-fired electric utilities. Ecol. Econ., 18: 161-175.

Färe, R., Grosskopf, S. and Sancho, H. (1999). Environmental performance: an index number approach. Department of Economics Working Paper. Oregon State University, Corvallis, Oregon.

Färe, R., Grosskopf, S. and Zaim, 0., (2003). An Environmental Kuznets Curve for the OECD countries. In: Färe, R., Grosskopf, S. (Eds.), New Directions: Efficiency and Productivity. Kluwer Academic Publishers, 79-90. 
Farrell, M. J. (1957). The measurement of productive efficiency. J. R. Stat. Soc., Series A, 120(3):253-290.

Golan, A., Judge, G., and Miller, D. (1996). Maximum Entropy Econometrics: Robust Estimation with Limited Data. John Wiley \& Sons, Chichester.

Halamay, D.A. and Brekken. T.K.A. (2011). Monte Carlo analysis of the impacts of high_renewable power penetration. Energy Conversion Congress and Exposition (ECCE), -IEEE, 3059-3066.

Halkos, G.E. and Tzeremes, N.G. (2009). Exploring the existence of Kuznets curve in countries' environmental efficiency using DEA window analysis, Ecol. Econ. 68(7): 2168-2176, ISSN 0921-8009, http://dx.doi.org/10.1016/j.ecolecon.2009.02.018

Haynes, K.E., S. Ratick, W.M. Bowen and Cummings-Saxton J. (1993) Environmental Decision Models: U.S. Experience and a New Approach to Pollution Management. Environ. Int., 19: 261-75.

Huppes, G., and Ishikawa, M. (2009). Eco-efficiency guiding micro-level actions towards sustainability: Ten basic steps for analysis, Ecol. Econ., 68(6): 1687-1700, ISSN 0921-8009, http://dx.doi.org/10.1016/j.ecolecon.2009.01.007.

Huppes, G. (2007). Realistic eco-efficiency analysis. Why we need better ecoefficiency analysis. From technological optimism to realism. Technikfolgenabschätzung - Theorie und Praxis 3 (16), 38-45.

IPCC, 2007. Climate Change 2007: Mitigation. Contribution of Working Group III to the Fourth Assessment Report of the Intergovernmental Panel on Climate Change [Metz, B., O.R. Davidson, P.R. Bosch, R. Dave, L.A. Meyer (eds.)]. Cambridge University Press.

Jaynes, E. T. (1957a). Information theory and statistical mechanics. Phys. Rev., 106(4):620-630.

Jaynes, E. T. (1957b). Information theory and statistical mechanics. II. Phys. Rev., 108(2):171-190.

Kabouris, J. and Kanellos, F. (2010). Impacts of Large scale Wind Penetration on Designing and Operation of Electric Power Systems. IEEE Trans. on Sustain. Energ., 1(2): 107-114.

Kortelainen, M. and Kuosmanen, T. (2005). Measuring Eco-efficiency of Production: A Frontier Approach. EconWPA, Working Paper 0411004. Washington University, St. Louis.

Kumbhakar, S. C. and Lovell, C. A. K. (2000). Stochastic Frontier Analysis. Cambridge University Press, Cambridge.

Lomborg, B. (2001). The sceptical environmentalist: Measuring the real state of the world. Cambridge: Cambridge University Press. 
Lovins, A. (1998). Factor four: Doubling wealth - halving resource use. London: Earthscan.

Lovins, A. (2011). Reinventing fire: Bold business solutions for new energy era. White River Junction, Vt: Chelsea Green Publishing.

Macedo, P. and Scotto, M. (2014). Cross-entropy estimation in technical efficiency analysis. J. Math. Econ., 54: 124-130.

Macedo, P., Silva, E., and Scotto, M. (2014). Technical efficiency with statecontingent production frontiers using maximum entropy estimators. J. Prod. Anal., 41(1):131-140.

Mandal, S.K. (2010). Do undesirable output and environmental regulation matter in energy efficiency analysis? Evidence from Indian Cement Industry, Energ. Policy, 38(10): 6076-6083, ISSN 0301-4215, http://dx.doi.org/10.1016/j.enpol.2010.05.063.

Meeusen, W. and van den Broeck, J. (1977). Efficiency estimation from CobbDouglas production functions with composed error. Int. Econ. Rev., 18(2):435-444.

OECD, Organization for Economic Co-operation and Development (1998). Ecoefficiency, OECD, Paris.

Picazo-Tadeo, A.J., Beltrán-Esteve, M. and Gómez-Limón, J.A. (2012). Assessing ecoefficiency with directional distance functions, Eur. J. Oper. Res., 220(3): 798-809, ISSN 0377-2217, http://dx.doi.org/10.1016/j.ejor.2012.02.025.

Picazo-Tadeo, A.J., Gómez-Limón, J.A. and Reig-Martínez, E. (2011). Assessing farming eco-efficiency: A Data Envelopment Analysis approach. J. Environ. Manage., $\quad$ 92(4): 1154-1164, ISSN 0301-4797, http://dx.doi.org/10.1016/j.jenvman.2010.11.025.

Picazo-Tadeo, J.A. and Prior, D. (2009). Environmental externalities and efficiency measurement. J. Environ. Manage., 90(11): 3332-3339, ISSN 0301-4797, http://dx.doi.org/10.1016/j.jenvman.2009.05.015.

Rashidi, K., Shabani, A. and Saen R. (2014). Using data envelopment analysis for estimating energy saving and undesirable output abatement: a case study in the Organization for Economic Co-Operation and Development (OECD) countries. Journal of Cleaner Production, Available online 9 August 2014, ISSN 0959-6526, http://dx.doi.org/10.1016/j.jclepro.2014.07.083.

Rezek, J. P., Campbell, R. C., and Rogers, K. E. (2011). Assessing total factor productivity growth in Sub-Saharan African agriculture. J. Agr. Econ., 62(2):357374.

Schmidheiny, S. and Zorraquin, J.L., (1996). Financing Change, the Financial Community, Eco-Efficiency and Sustainable Development. MIT Press, Cambridge, MA. 
Taskin, F. and Zaim, 0. (2000). Searching for a Kuznets curve in environmental efficiency using kernel estimations. Econ. Lett., 68: 217-223.

Tyteca, D. (1996). On the Measurement of the Environmental Performance of Firms- A Literature Review and a Productive Efficiency Perspective. J. Environ. Manage., 46: 281-308.

Tyteca, D. (1997). Linear programming models for the measurement of environmental performance of firms: concepts and empirical results. J. Prod. Anal., 8:175-189.

Wursthorn, S., Poganietz W. and Schebek, L. (2011). Economic-environmental monitoring indicators for European countries: A disaggregated sector-based approach for monitoring eco-efficiency, Ecol. Econ., 70, Issue 3, 15, Pages 487-496.

Zaim, 0. (2004). Measuring environmental performance of state manufacturing through changes in pollution intensities: a DEA framework. Ecol. Econ., 48: 37-47.

Zaim, 0. and Taskin, F. (2000). A Kuznets curve in environmental efficiency: an application on OECD countries. Environ. Resour. Econ., 17: 21-36.

Zaim, O., Färe, R. and Grosskopf, S. (2001). An economic approach to achievement and improvement indexes. Soc. Indic. Res., 56: 91-118.

Zhou P., Ang, B.W. and Poh, K.L. (2006) Slacks-based efficiency measures for modelling environmental performance. Ecol. Econ., 60:111-118.

Zhou P., Poh, K.L., Ang., B.W. (2007) A non-radial DEA approach to measuring environmental performance. Eur. J. Oper. Res., 178: 1-9.

Zofio, J.L., Prieto, A.M. (2001) Environmental efficiency and regulatory standards: the case of $\mathrm{CO} 2$ emissions from OECD industries. Resour. Energy Econ., 23: 63-83.

Zhu, Z., Wang, K. and Zhang B. (2014). A network data envelopment analysis model to quantify the eco-efficiency of products: a case study of pesticides, Journal of Cleaner Production, Volume 69, Pages 67-73. 


\section{Appendix}

Table A1- Eco-Efficiency in European Countries through Generalized Maximum Entropy (GME), Generalized Cross-Entropy (GCE) and Maximum Likelihood (ML) estimators

\begin{tabular}{|c|c|c|c|c|c|c|c|c|c|c|c|c|}
\hline & \multicolumn{3}{|c|}{2000} & \multicolumn{3}{|c|}{2001} & \multicolumn{3}{|c|}{2002} & \multicolumn{3}{|c|}{2003} \\
\hline & GME & GCE & ML & GME & GCE & ML & GME & GCE & ML & GME & GCE & $\mathrm{ML}$ \\
\hline Belgium & 0,6740 & 0,7851 & 0,8066 & ,7079 & ,7731 & , 8391 & 0,6947 & 0,7640 & 1,8237 & 0,7079 & ,7655 & 3352 \\
\hline Bulgaria & 0,7225 & 0,8170 & 0,8309 &, 7035 & ,7694 & 0,8321 & 0,6942 & 0,7634 & 0,8211 & 0,6730 &, 7351 & 0,7859 \\
\hline Czech Republic & 0,4971 & 0,6387 & 0,5257 & 0,5433 & 0,6205 & 0,6349 & 0,5144 & 0,5947 & 0,5445 & 0,5319 &, 5984 & 593 \\
\hline Denmark & 0,6816 & 0,7906 & 0,7954 & 0,6949 & 0,7623 & 0,8252 & 0,6932 & 0,7619 & 0,8023 & 0,6778 & 0,7382 & 0,7620 \\
\hline Germany & 6392 & 0,7607 & 0,7673 &, 6741 & 0,7452 & 0,8046 & 0,6 & 0,7373 & 0,7736 & 0,6621 & 0,7263 & 0,7663 \\
\hline Estonia & 0,4 & 0,5990 & 0,5398 & 0,5 & 0,5 & & & 92 & & & & \\
\hline Irelc & 0,5696 & 0,7061 & 0,6349 & 0,6050 & 0,6828 & 0,7199 & & 0,6998 & 0,7 & 64 & 0,6832 & 0,6782 \\
\hline Gre & ,5826 & 0,7173 & 0,6770 & 0,6168 & 0,6938 & 0, & 0,5 & 0,6690 & 89 & 62 & & \\
\hline Spain & 0,6079 & 0,7374 & 0,7205 & 0,6430 & 0,7180 & 0,7677 & 0,6088 & 0,6892 & 0,6849 & 0,6083 & 0,6760 & 0,6698 \\
\hline & 73 & 0,8254 & 0,8 & 0,7723 & 0,8221 & & & 0,8075 & & & 0,8010 & 761 \\
\hline Italy & 0,7034 & 0,8043 & 0,8470 & 0,7130 & 0,7772 & 0,8439 & 0,6817 & 0,7532 & 0,8023 & 0,6790 & 0,7410 & 0,7924 \\
\hline & & 0,8416 & & $0, \varepsilon$ & 0,8489 & & & 50 & & & 345 & \\
\hline Latvia & 0,7699 & 0,8452 & & & 0,8 & & & 0,8 & & 0,7 & 0,8 & 986 \\
\hline Lithuar & ,7432 & 0,8295 & 0,8669 & 0,7 & 0,7929 & 0,8 & 0 , & 0,7927 & & & 0,7828 & \\
\hline & & 0,8 & 0,8 & 0 , & & 47 & & & & & & \\
\hline Hur & 0,6589 & 0,7753 & 0,7718 & 0,7077 & 0,7727 & 0,8371 & 0,6902 & 500 & 0 & 0,7017 & 596 & 0,8256 \\
\hline Net & 6967 & 0,8000 & 0,8433 & 0,7139 & 0,7779 & 0,8449 & 0,7200 & 336 & 08 & 0, & 0,7752 & 0,8466 \\
\hline Austria & 6911 & 0,7967 & 0,8177 & 0,7241 & 0,7856 & 0,8521 & 0,7 & 0,7842 & 0,8 & & 0,7652 & 0,8173 \\
\hline & 5367 & 0,6772 & 0,6371 & 0,6134 & 0,6906 & 0,7284 & $0, \epsilon$ & 0,6922 & 40 & 0, & 0,6877 & 0,7003 \\
\hline & 0,6377 & 0,7602 & 0,7436 & 0,6 & 0,7 & 0, & & 373 & & & 0,7613 & 0,8043 \\
\hline Ror & 0,7531 & 0,8353 & 0,8974 & 0,7899 & 0,8347 & 0,8979 & 0,7 & 0,8027 & & 0 , & 0,7802 & 0,8566 \\
\hline & & & & & & & & & & & 17 & \\
\hline & 6543 & 0,7720 & 0,7566 & 0,6390 & 0,7143 & 0,7616 & 0 , & 0,7253 & 0,7 & 0 , & 0,7321 & 0,7838 \\
\hline Finland & 0,6458 & 0,7662 & 0,7579 & 0,6777 & 0,7479 & 0,8058 & 0,6 & 0,7349 & 0,7588 & 0,6446 & 0,7090 & 0,7134 \\
\hline & 0,8386 & 0,8836 & 0,9304 & 0,8545 & 0,8799 & 0,9290 & & 0,8790 & 0,9365 & 0,8611 & 0,8798 & 0,9372 \\
\hline United $\mathrm{K}$ & 0,7807 & 0,8504 & 0,9074 & 0,7842 & 0,8309 & 0,8970 & 0,7771 & 0,8258 & 0,9017 & 0,7667 & 0,8120 & 0,8940 \\
\hline Mean & 0,6696 & 0,7768 & $0,7 \varepsilon$ & 0,69 & 0,7599 & 0,81 & 0,68 & 0,7496 & $0,7 \varepsilon$ & 0,6830 & 0,7390 & 0,7763 \\
\hline & 0,0896 & 0,0665 & 0,1093 & 0,0800 & 0,0679 & 0,0818 & 0,0842 & 0,0731 & 0,1111 & 0,0868 & 0,0791 & 0,1183 \\
\hline Minimum & 0,4588 & 0,5990 & 0,5257 & 0,5134 & 0,5879 & 0,5928 & 0,4651 & 0,5392 & 0,4612 & 0,4361 & 0,4888 & 0,4068 \\
\hline Maximum & 0,8386 & 0,8836 & 0,9304 & 0,8545 & 0,8799 & 0,9290 & 0,8538 & 0,8790 & 0,9365 & 0,8611 & 0,8798 & 0,9372 \\
\hline
\end{tabular}

\begin{tabular}{|c|c|c|c|c|c|c|c|c|c|c|c|c|}
\hline & \multicolumn{3}{|c|}{2004} & \multicolumn{3}{|c|}{2005} & \multicolumn{3}{|c|}{2006} & \multicolumn{3}{|c|}{2007} \\
\hline & GME & GCE & $\mathrm{ML}$ & GME & GCE & ML & GME & GCE & $\mathrm{ML}$ & GME & GCE & $\mathrm{ML}$ \\
\hline Belgium & 0,6910 & 0,7592 & 0,8181 & 0,6781 & 0,7551 & 0,7933 & 0,6732 & 0,7612 & 0,7886 & 0,6742 & 0,7671 & 0,8313 \\
\hline Bulgaria & 0,6745 & 0,7451 & 0,7859 & 0,6399 & 0,7231 & 0,7212 & 0,6247 & 0,7228 & 0,6885 & 0,6268 & 0,7311 & 0,6533 \\
\hline Czech Rep & 0,5411 & 0,6202 & 0,5673 & 0,5488 & 0,6375 & 0,5608 & 0,5406 & 0,6457 & 0,5313 & 0,5217 & 0,6352 & 0,4893 \\
\hline Denmark & 0,7039 & 0,7684 & 0,8101 & 0,7114 & 0,7805 & 0,8115 & 0,6436 & 0,7374 & 0,6229 & 0,6569 & 0,7535 & 0,6383 \\
\hline Germany & 0,6602 & 0,7334 & 0,7604 & 0,6620 & 0,7418 & 0,7602 & 0,6395 & 0,7343 & 0,7062 & 0,6327 & 0,7347 & 0,6755 \\
\hline Estonia & 0,4416 & 0,5085 & 0,4108 & 0,4470 & 0,5255 & 0,3937 & 0,4315 & 0,5279 & 0,3218 & 0,3955 & 0,4950 & 0,2679 \\
\hline Ireland & 0,6141 & 0,6917 & 0,6767 & 0,5907 & 0,6781 & 0,6095 & 0,6040 & 0,7043 & & 0,6141 & 0,7195 & \\
\hline Greece & 0,5864 & 0,6651 & 0,6265 & 0,6154 & 0,7010 & 0,6576 & 0,5957 & 0,6970 & 0,5865 & 0,5274 & 0,6404 & 0,4650 \\
\hline Spain & 973 & 0,6761 & 0,6491 & 0,5855 & 0,6733 & 0,6 & 47 & 0,6777 & & & 0,6805 & 0,5402 \\
\hline France & 0,7442 & 0,8006 & 0,8739 & 0,7290 & 0,7942 & 0,8667 & 0,7228 & 0,7975 & 0,8744 & 0,7147 & 0,7958 & 0,8654 \\
\hline Italy & 0,6703 & 0,7419 & 0,7795 & 0,6745 & 0,7522 & 0,7771 & 0,6664 & 0,7557 & 0,7445 & 0,6677 & 0,7620 & 0,7649 \\
\hline Cyprus & 0,7894 & 0,8331 & 0,9136 & 0,7974 & 0,8425 & 0,9243 & 0,7778 & 0,8352 & 0,9 & 0,7664 & 0,8308 & 0,9824 \\
\hline Latvia & 0,7675 & 0,8167 & 0,8864 & 0,7427 & 0,8038 & 0,8635 & 0,7400 & 0,8097 & 0,8483 & 0,7654 & 0,8299 & 0,8793 \\
\hline & & & & & & & & & & & & \\
\hline Luxembou & 0,6942 & 0,7620 & 0,8321 & 0,6882 & 0,7634 & 0,8304 & 0,6642 & 0,7548 & 0,8273 & 0,6520 & 0,7507 & 0,9436 \\
\hline Hungary & 0,7048 & 0,7699 & 0,8302 & 0,7280 & 0,7937 & 0,8638 & 0,7495 & 0,8164 & 0,9355 & 0,7566 & 0,8246 & 0,9847 \\
\hline Netherlan & 0,7325 & 0,7918 & 0,8689 & 0,7390 & 0,8017 & 0,8749 & 0,7248 & 0,7990 & 0,8655 & 0,7165 & 0,7973 & 0,8863 \\
\hline Austria & 0,7140 & 0,7769 & 0,8321 & 0,7134 & 0,7824 & 0,8396 & 0,7267 & 0,8003 & 0,8671 & 0,7418 & 0,8143 & 0,9157 \\
\hline Poland & 0,6266 & 0,7037 & & & & & & & & & & 0,6058 \\
\hline Portugal & 0,7056 & 0,7699 & 0,8140 & 0,7013 & 0,7729 & 0,8028 & 0,7309 & 0,8032 & 0,8323 & 0,7467 & 0,8176 & 0,8343 \\
\hline Romania & 0,7425 & 0,7996 & & 0,7440 & 0,8058 & 0,8976 & & 0,7806 & 0,8848 & 0,6668 & 0,7624 & 0,7664 \\
\hline Slovenia & 0,7063 & 0,7704 & 0,8198 & 0,7107 & 0,7802 & 0,8246 & 0,6961 & 0,7786 & 0,7840 & 0,6847 & 0,7749 & 0,7441 \\
\hline Slovakia & 0,6762 & 0,7467 & 0,7880 & 0,6801 & 0,7568 & 0,7905 & 0,6728 & 0,7614 & 0,7826 & 0,7008 & 0,7868 & 0,8310 \\
\hline Finland & 0,6578 & 0,7303 & 0,7345 & 0,6952 & 0,7680 & 0,8065 & 0,6500 & 0,7429 & 0,6990 & 0,6476 & 0,7465 & 0,6791 \\
\hline Sweden & 0,8553 & 0,8790 & 0,9430 & 0,8406 & 0,8714 & 0,9456 & 0,8273 & 0,8667 & 0,9566 & 0,8158 & 0,8613 & 0,9803 \\
\hline United Kingdom & 0,7598 & 0,8125 & 0,8970 & 0,7689 & 0,8233 & 0,9056 & 0,7579 & 0,8216 & 0,9190 & 0,7428 & 0,8150 & 0,9571 \\
\hline Mean & 0,6837 & 0,7482 & 0,7825 & 0,6841 & 0,7552 & 0,7795 & 0,6705 & 0,7544 & 0,7516 & 0,6636 & 0,7531 & 0,7477 \\
\hline Std. Deviation & 0,0831 & 0,0738 & 0,1188 & 0,0813 & 0,0705 & 0,1263 & 0,0832 & 0,0696 & 0,1530 & 0,0915 & 0,0774 & 0,1841 \\
\hline
\end{tabular}




\begin{tabular}{|c|c|c|c|c|c|c|c|c|c|c|c|c|}
\hline Minimum & 0,4416 & 0,5085 & 0,4108 & 0,4470 & 0,5255 & 0,3937 & 0,4315 & 0,5279 & 0,3218 & 0,3955 & 0,4950 & 0,2679 \\
\hline \multirow[t]{3}{*}{ Maximum } & 0,8553 & 0,8790 & 0,9430 & 0,8406 & 0,8714 & 0,9456 & 0,8273 & 0,8667 & 0,9566 & 0,8158 & 0,8613 & 0,9847 \\
\hline & \multicolumn{3}{|c|}{2008} & \multicolumn{3}{|c|}{2009} & \multicolumn{3}{|c|}{2010} & \multicolumn{3}{|c|}{2011} \\
\hline & GME & GCE & ML & GME & GCE & ML & GME & GCE & ML & GME & GCE & ML \\
\hline Belgium & 0,6669 & 0,7648 & 0,7958 & 0,6786 & 0,7535 & 0,7982 & 0,6540 & 0,7492 & 0,7563 & 0,6449 & 0,7568 & 0,7309 \\
\hline Bulgaria & 0,5587 & 0,6771 & 0,4684 & 0,5557 & 0,6415 & 0,5085 & 0,5579 & 0,6664 & 0,5076 & 0,5459 & 0,6762 & 0,5295 \\
\hline Czech Republic & 0,5036 & 0,6226 & 0,4379 & 0,5197 & 0,6044 & 0,4920 & 0,4880 & 0,5955 & 0,4401 & 0,4594 & 0,5899 & 0,4097 \\
\hline Denmark & 0,6518 & 0,7530 & 0,6910 & 0,6818 & 0,7558 & 0,7626 & 0,6682 & 0,7597 & 0,7620 & 0,6352 & 0,7484 & 0,7044 \\
\hline Germany & 0,6223 & 0,7296 & 0,6296 & 0,6574 & 0,7356 & 0,7274 & 0,6292 & 0,7291 & 0,6760 & 0,5783 & 0,7037 & 0,5676 \\
\hline Estonia & 0,4153 & 0,5262 & 0,3114 & 0,5106 & 0,5946 & 0,4610 & 0,4493 & 0,5529 & 0,3715 & 0,3614 & 0,4755 & 0,2882 \\
\hline Ireland & 0,6223 & 0,7304 & 0,6832 & 0,6982 & 0,7691 & 0,8189 & 0,7330 & 0,8069 & 0,9047 & 0,7337 & 0,8169 & 0,9506 \\
\hline Greece & 0,5661 & 0,6824 & 0,5345 & 0,6024 & 0,6868 & 0,6189 & 0,6034 & 0,7073 & 0,6260 & 0,6244 & 0,7412 & 0,6778 \\
\hline Spain & 0,5816 & 0,6957 & 0,5476 & 0,6371 & 0,7181 & 0,6785 & 0,6511 & 0,7467 & 0,7184 & 0,6235 & 0,7402 & 0,6567 \\
\hline France & 0,6944 & 0,7841 & 0,7838 & 0,7151 & 0,7820 & 0,8386 & 0,7161 & 0,7951 & 0,8473 & 0,6903 & 0,7884 & 0,7727 \\
\hline Italy & 0,6648 & 0,7629 & 0,7184 & 0,6957 & 0,7670 & 0,8003 & 0,6734 & 0,7641 & 0,7748 & 0,6447 & 0,7564 & 0,7039 \\
\hline Cyprus & 0,7362 & 0,8137 & 0,9286 & 0,7188 & 0,7851 & 0,8484 & 0,6969 & 0,7815 & 0,8232 & 0,7147 & 0,8048 & 0,9214 \\
\hline Latvia & 0,8031 & 0,8559 & 0,9921 & 0,8124 & 0,8518 & 0,9342 & 0,8341 & 0,8725 & 0,9487 & 0,7746 & 0,8421 & 0,9506 \\
\hline Lithuania & 0,6770 & 0,7728 & 0,6772 & 0,7772 & 0,8276 & & 0,7243 & 0,8009 & 0,8190 & 0,6474 & 0,7582 & 0,7150 \\
\hline Luxembourg & 0,6304 & 0,7373 & 0,8879 & 0,6682 & 0,7456 & 0,8401 & 0,6291 & 0,7295 & 0,7557 & 0,5755 & 0,7024 & 0,6395 \\
\hline Hungary & 0,7527 & 0,8243 & 0,9023 & 0,7342 & 0,7967 & 0,8618 & 0,7313 & 0,8061 & 0,8513 & 0,7618 & 0,8348 & 0,9498 \\
\hline Netherlands & 0,6978 & 0,7868 & 0,8123 & 0,7268 & 0,7912 & 0,8620 & 0,7093 & 0,7904 & 0,8735 & 0,6397 & 0,7526 & 0,7469 \\
\hline Austria & 0,7201 & 0,8019 & 0,8717 & 0,7224 & 0,7876 & 0,8536 & 0,7206 & 0,7982 & 0,8522 & 0,6874 & 0,7864 & 0,7721 \\
\hline Poland & 0,5677 & 0,6841 & 0,5060 & 0,5654 & 0,6514 & 0,5495 & 0,5450 & 0,6541 & 0,5055 & 0,5049 & 0,6373 & 0,4562 \\
\hline Portugal & 0,7265 & 0,8065 & 0,7944 & 0,7163 & 0,7829 & 0,8122 & 0,7321 & 0,8061 & 0,8513 & 0,7423 & 0,8219 & 0,9058 \\
\hline Romania & 0,6432 & 0,7482 & 0,5728 & 0,6940 & 0,7660 & 0,7533 & 0,6716 & 0,7635 & 0,6625 & 0,6477 & 0,7598 & 0,6815 \\
\hline Slovenia & 0,6609 & 0,7609 & 0,7250 & 0,6937 & 0,7656 & 0,7956 & 0,7241 & 0,8010 & 0,8422 & 0,7393 & 0,8206 & 0,9215 \\
\hline Slovakia & 0,7125 & 0,7979 & 0,8090 & 0,7328 & 0,7956 & 0,8547 & 0,6942 & 0,7798 & 0,7954 & 0,6077 & 0,7282 & 0,6603 \\
\hline Finland & 0,6526 & 0,7538 & 0,7189 & 0,6446 & 0,7248 & 0,7098 & 0,6275 & 0,7278 & 0,6524 & 0,6492 & 0,7596 & 0,6750 \\
\hline Sweden & 0,7809 & 0,8409 & 0,9707 & 0,8051 & 0,8466 & 0,9305 & 0,7892 & 0,8434 & 0,9326 & 0,7776 & 0,8429 & 0,9544 \\
\hline United Kingdom & 0,7708 & 0,8351 & 0,9637 & 0,8129 & 0,8523 & 0,9399 & 0,7696 & 0,8313 & 0,9350 & 0,7357 & 0,8181 & 0,9387 \\
\hline Mean & 0,6569 & 0,7519 & 0,7205 & 0,6837 & 0,7530 & 0,7671 & 0,6701 & 0,7561 & 0,7494 & 0,6441 & 0,7486 & 0,7262 \\
\hline Std. Deviation & 0,0889 & 0,0728 & 0,1800 & 0,0818 & 0,0694 & 0,1381 & 0,0886 & 0,0734 & 0,1556 & 0,0994 & 0,0834 & 0,1805 \\
\hline Minimum & 0,4153 & 0,5262 & 0,3114 & 0,5106 & 0,5946 & 0,4610 & 0,4493 & 0,5529 & 0,3715 & 0,3614 & 0,4755 & 0,2882 \\
\hline Maximum & 0,8031 & 0,8559 & 0,9921 & 0,8129 & 0,8523 & 0,9399 & 0,8341 & 0,8725 & 0,9487 & 0,7776 & 0,8429 & 0,9544 \\
\hline
\end{tabular}


Figure A1- Variation of: Average Productivity of Capital (GDP/K), Average Productivity of Labour (GDP/L), Fossil Fuel Intensity (F/GDP) and Renewable Energy Intensity (R/GDP)

Figure A1a - Countries with good performance

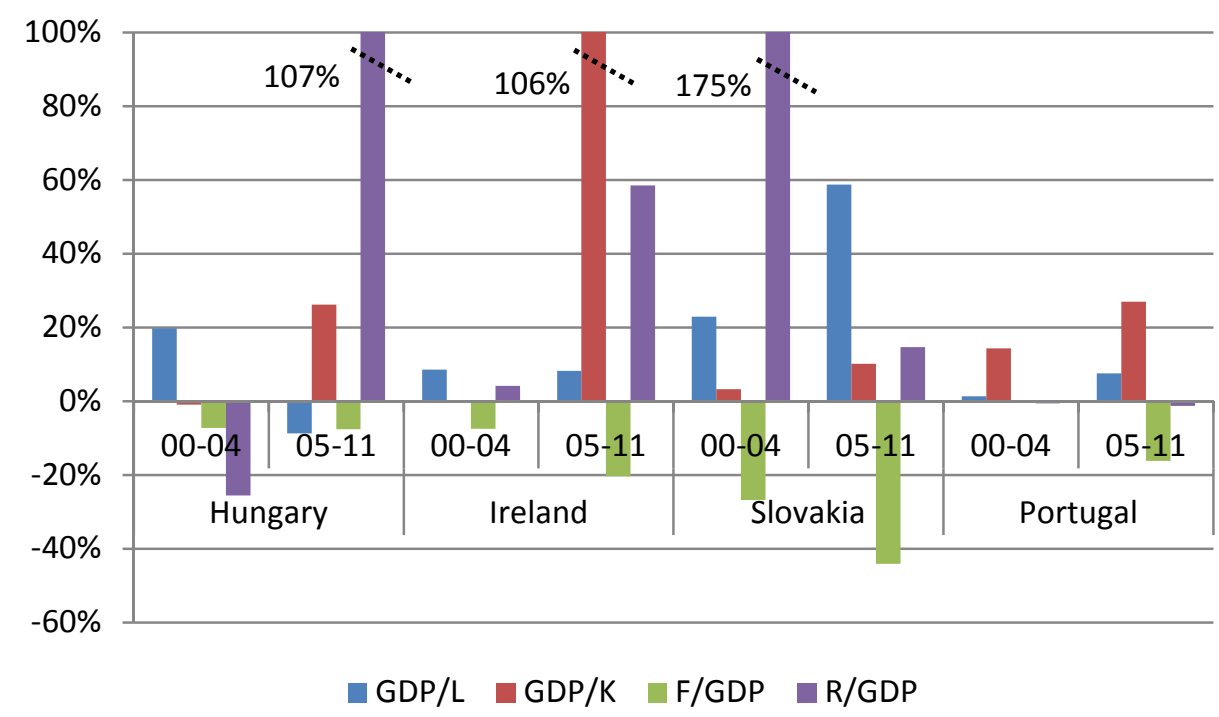

Figure A1b -Countries with less good performance

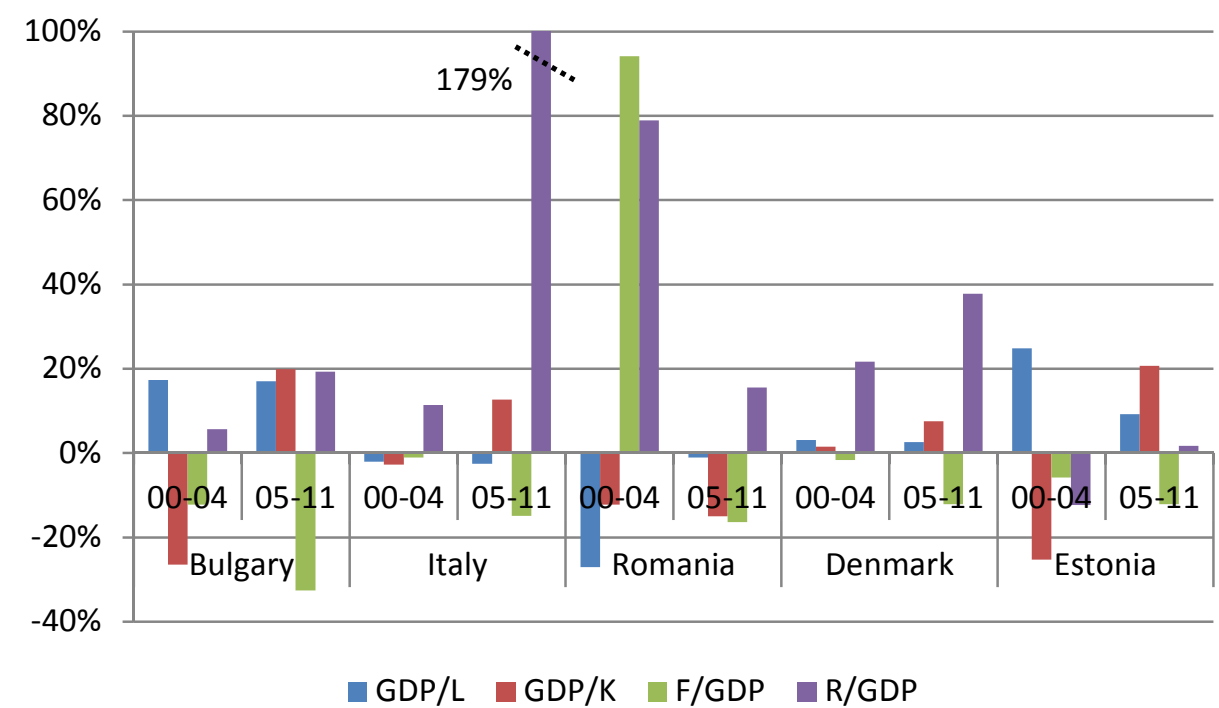


Figure A2a - Eco-Efficiency estimates in 2000-2011 provided by the GME estimator

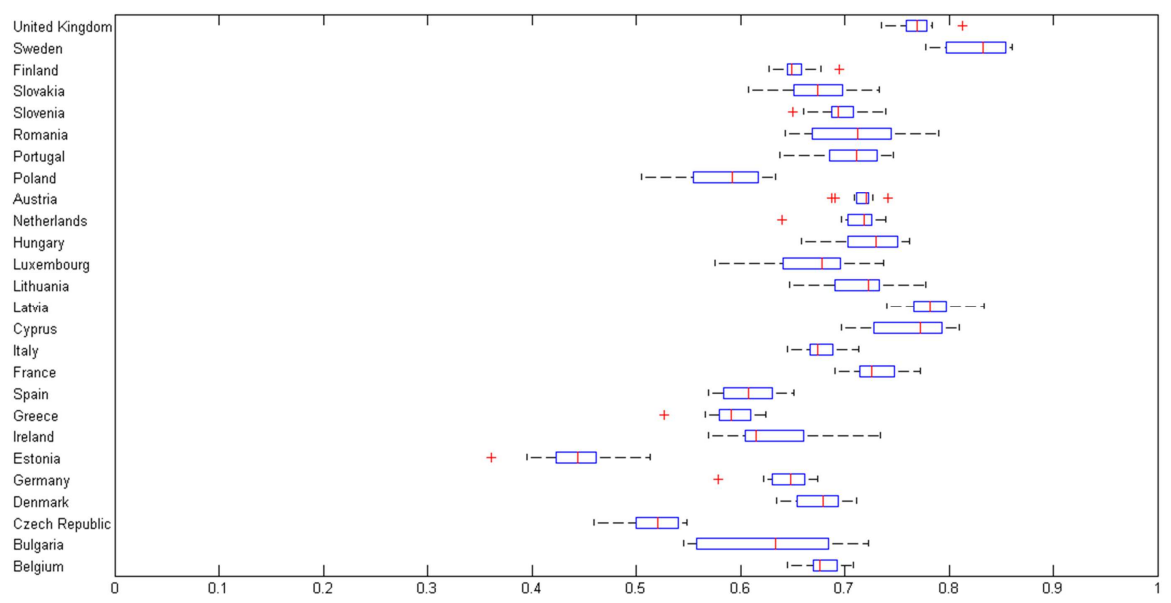

Figure A2b - Eco-Efficiency estimates in 2000-2011 provided by the GCE estimator

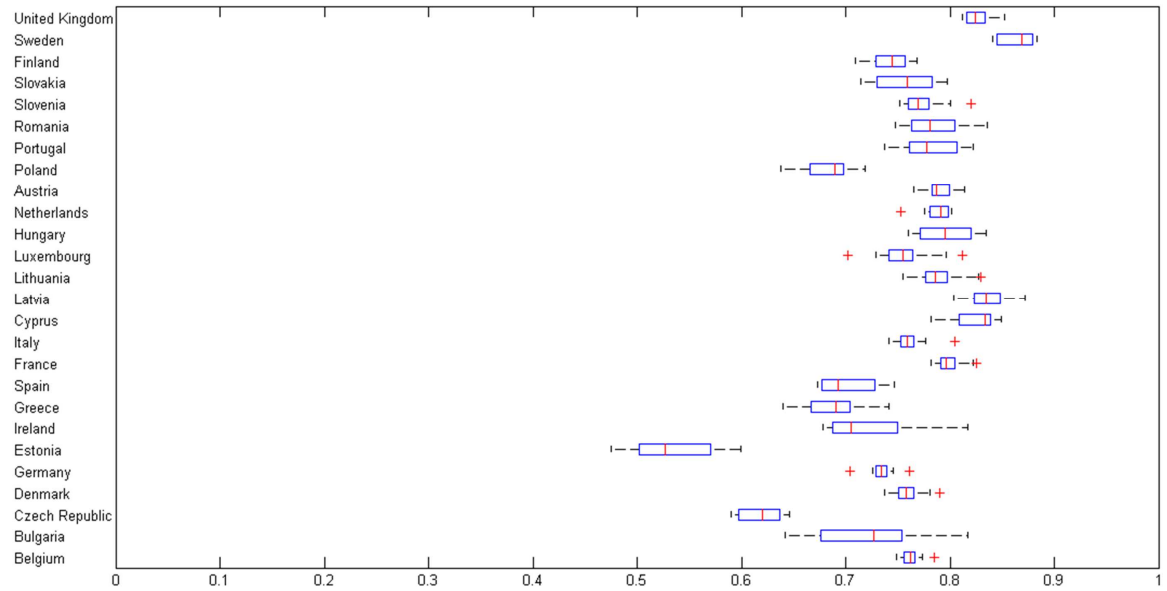

Figure A2c - Eco-Efficiency estimates in 2000-2011 provided by the ML estimator

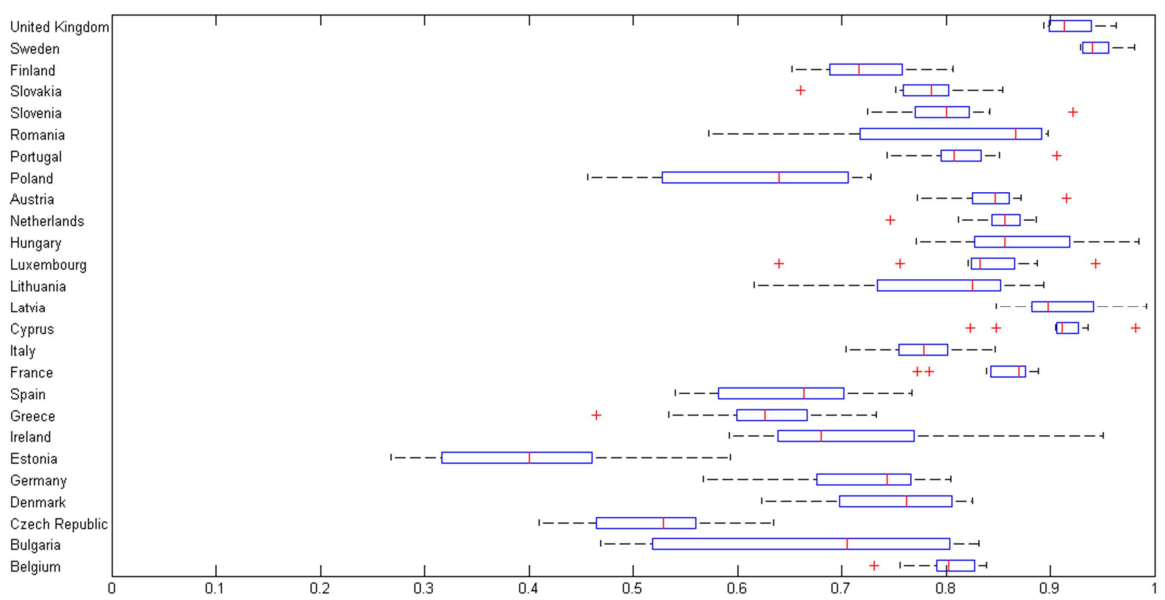

